\title{
ASPECTS OF VERIFICATION AND OPTIMIZATION OF SHEET METAL NUMERICAL SIMULATIONS PROCESS USING THE PHOTOGRAMMETRIC SYSTEM
}

\author{
Wiestaw Fracz, ${ }^{1)^{*}}$, Feliks Stachowicz ${ }^{1)}$, Tomasz Pieja ${ }^{2)}$ \\ ${ }^{1)}$ Rzeszow University of Technology, Faculty of Mechanical Engineering and Aeronautics, \\ Rzeszow, Poland \\ ${ }^{2)}$ WSK PZL Rzeszow S.A., Rzeszow, Poland
}

Received 27.06.2012

Accepted 26.11.2012

*Corresponding author: e-mail: wf@prz.edu.pl, Tel.: +48178651714, Department of Materials and Processing, Faculty of Mechanical Engineering and Aeronautics, Rzeszow University of Technology, al. Powstancow Warszawy 12, 35-959 Rzeszów, Poland

\begin{abstract}
The paper presents the use of photogrammetric system for verification and optimization of the numerical simulation of sheet metal forming process. The use of GOM Argus photogrammetric system allowed determining the real values of the analyzed drawpiece strains, construction of real Forming Limit Curve (FLC) and comparing them with the limit strain values resulting from the FLC. The knowledge of the drawpiece real strain distribution in the sheet metal forming optimization process allows, by using the numerical simulation in the eta/Dynaform commercial software, to estimate the optimum value of the friction coefficient that was taken into account in the numerical simulation. The GOM Argus system was also used to assess the impact of selected technological parameters on the accuracy of sheet metal forming drawpiece shape in comparison with the theoretical CAD model. An attempt to optimize the process to obtain the correct geometry of the drawpiece has been also carried out.
\end{abstract}

Keywords: sheet metal, numerical simulations, strain analysis, optical measurement.

\section{Introduction}

Numerical simulations of sheet metal plastic forming processes are becoming a common practice. Numerical analysis can provide in-depth look at the technological process and determine the optimal parameters. The results of such numerical simulations can be surprising, sometimes even far from the results of a physical experiment. To be sure a physical model of the process is often carried out. Although its implementation remains a problem with its fast and accurate strain measurement and comparison with the results of the numerical simulations. Conventionally, experimental strains are determined by manual strain measurement methods. Before forming, a grid pattern which is defined as one or more lines, dots or other shapes is applied to the sheet metal surface. Grid patterns are printed on the sheet metal surface using more often the electro-chemical etching method [1]. During the stamping operation, the grid pattern deforms with the material, and then the surface strains can be measured from the deformed pattern by comparing its size to the original size of the grid pattern. Types of tools used in manual measurement include dividers, a ruler, and a graduated transparent tape or a microscope [2]. The manual strain measurement methods are time consuming and have low 
accuracy. As a result, automated surface strain measurement systems have been developed. These systems were developed based on close range industry photogrammetry and have become important tools in industrial tool making and sheet metal forming processes in the last years. This type of method can be used for dynamic surface strain measurement too. However, BaoQuan Shi et al. [3] say that this method cannot be used in some of the sheet metal processes, such as deep drawing or stamping.

The key technologies of the photogrammetry measurement process are very complex and consist of noising reduction, adaptive thresh holding, sub-pixel edge detection, least square ellipse fitting, camera calibration, grid node matching and reconstruction, 3D grid generation and surface strain calculation. Vogel and Lee [4] introduced a well-known video camera-based system. This system includes a camera, a positioning device, a rotary table and a computer with software. Orteu et al. [5] improved the stereo vision strain measurement system by adopting robust and sophisticated algorithms for camera calibration. Recently, a digital image correlation method was applied to measure sheet metal surface strain with a random grid pattern $[6,7]$. Once the sheet metal has been pressed into desired shapes, images are recorded and imported into the measurement software. Then, the 3D grids are generated and the surface strains are calculated. Circular grid pattern measurement procedure and surface strain calculation method were presented in [3]. The surface strain calculation is often based on method proposed by Vogel and Lee [8]. The typical representatives of sheet metal strain measurement system applied in industrial field are the Argus system of GOM Company, the AutoGrid system of the ViaLux Company, the Grid Analyzer Model 100U of the FMTI Systems Inc., the TargetModel, 2DMode and GPA system of the ASAME Company and XJTUSM developed by Xi'an Jiaotong University in China. These systems can achieve high measurement accuracy [3].

One of the most popular and high accuracy systems is German Argus system of GOM Company. The hardware of the surface strain measurement system consists of electro-chemical etching equipment, high performance PC, system frame, trigger box, coded reference targets and highprecision scale bar. The ability of using this system is different. Andersson et al. [9] used Argus to detect deformations in deep-drawn parts and calculate material strain during experimental evaluation of strains in the tension-compression using a new X-Die tool geometry. By means this system the true strain has been used for strain evaluation. Chu et al. [10] used Argus to measure the maximum effective strain value from the deformed workpiece. On the other hand, the corresponding effective stress value was retrieved from the simulation. By combining the effective stress and effective strain data produced by different punch radii, the flow curve was established. By analyzing the deformation of the grid, the effective strain value can be easily retrieved. The maximum effective strain observed in the workpiece was measured and transformed into a Huber-Mises effective strain. The effective strain was a calculated physical value which made it possible to compare the strains under different deformation process. Argus system was used too for comparison experimental FLDs with predicted FLD in post-test periodic grid-based strain measurement procedure [11, 12]. A. Meyer et al. [13] analysed numerical and experimental cases of the increasing of the drawing depth using tailor rolled blanks by means Argus and Dynaform commercial code. Evaluating the results, section cuts through the deep drawn parts of the FE-results as well as of the experimental results were derived and compared to each other. For all that number of publications describing the extent of their usefulness and accuracy of measurements is still limited. Some of the analyzed GOM Argus system publications contain mostly advertisement materials [14-16], showing the capabilities of the system. The rest $[17,18]$, among analysed literature are examples of real 
system applications, but they do not present any opinion considering its accuracy. One of the objectives shown in this paper study was an attempt to present the broader aspects of the use of the photogrammetric GOM Argus system.

\section{Experimental materials and methods}

The subject of the research was the production drawpiece with the outer diameter of $180 \mathrm{~mm}$ (Fig. 1b), made of steel AMS 5512. The aim of this study was to evaluate the accuracy of the sheet metal forming process numerical simulations results in comparison to the physical model of the drawpiece, forming according to a new concept.

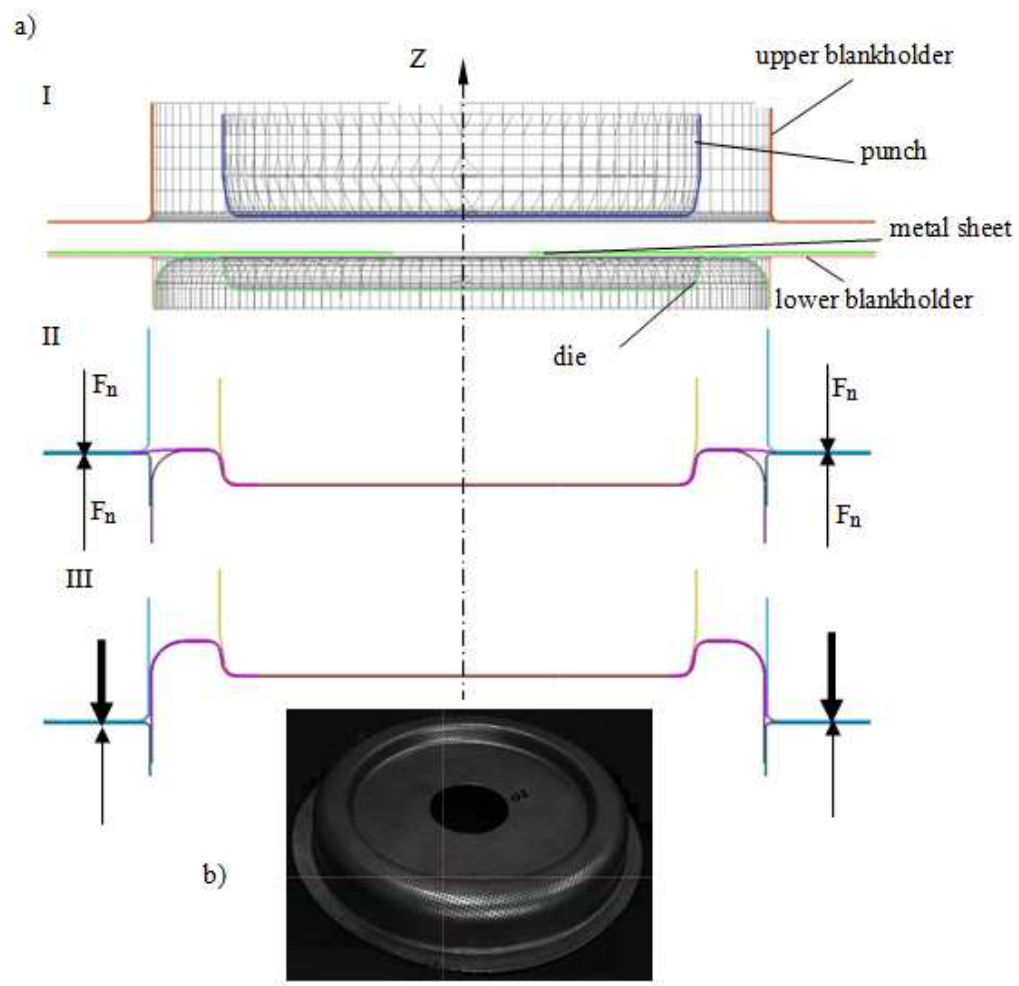

Fig. 1 Stages of sheet metal forming process (a) and drawpiece with measuring grid (b)

This drawpiece was formed in the stages shown in Fig. 1 using the triple-action hydraulic 260T Diefenbacher press type. Flat blank sheet with a central circular hole is positioned between blankholder. The blankholder, after moving to the sheet metal, exert contact pressure. The contact pressure can be adjusted by change up the pressure in the hydraulic system. In the first phase the upper blankholder pushes sheet metal under a pressure of $10 \mathrm{MPa}$. The optimal value of the pressure ensures the proper shape - dimensional accuracy of the drawpiece. After this stage the drawpiece bottom is shaped by means a punch. After shaping the drawpiece bottom the punch is still pressing the sheet to the die with maximum load to prevent deformation of the sheet in this area during the next stage of a process. Meanwhile, the lower blankholder begins to exert pressure on the upper blankholder. In analyzed several cases, the following values were used in the pressure system: $2 \mathrm{MPa}, 30 \mathrm{MPa}$, and $50 \mathrm{MPa}$. The upper blankholder is loaded by 
proper force in order to move both blankholder in the Z-axis direction and, so the stretch drawing of the sheet metal on the die is done. Achieving of the correct drawpiece height finishes the technological process. This additional forming stage stiffens the drawpiece. During the whole process only the die remains stationary. The force characteristics for each stage of the process are given in Fig. 2. The springback phenomenon occurred during the manufacturing process has little effect on the geometric shape of drawpiece. Before cutting the final shape the drawpiece is annealed to eliminate internal stress.

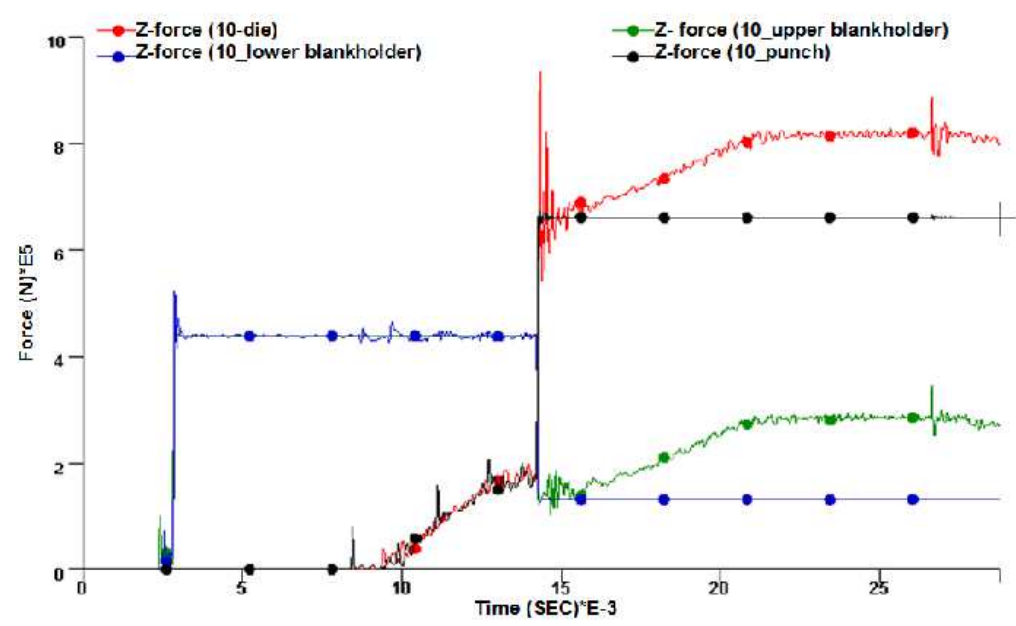

Fig. 2 Force characteristics of sheet metal forming process

\subsection{Course of study}

Before the experiment the properties of the AMS 5512 sheets were determined and series of numerical simulations of the process, in the commercial eta/Dynafom 5.7.3 software, were made [19]. The results obtained in the numerical simulations allowed expecting that a new concept of forming process is feasible. Use of the commercial software ensures the possibility of direct comparison of strain simulation results with the strains measured in the Argus system. The Argus contains a SVIEW application that allows to direct import of the file containing, among others, strains calculated in the simulation made in eta/Dynaform. The preparing of the technological process requires the verification of the numerical simulations results. Therefore the sheet blanks were prepared to form drawpiece. The measuring circular dots grid was electrochemically etched on the sheet metal surface. During the experiment, the blankholder force value was changed. The formed drawpiece were measured using the Argus system 5M. The simulation results were verified. Certain differences were found between the strains measured by using of the Argus system and the simulation results. Following this, the simulations with variable values of the friction coefficient was carried out. Its value, taken on the basis of similarity to other simulations can severely significantly influence on the simulation results. As a result of the simulation the optimum value of friction coefficient, at which was good agreement with the experiment result, was found. The better value of the friction coefficient can be used in further simulations conducted on this kind of sheet metal, forming tools and their surface roughness. In the final phase of study the numerical and physical model were compared in the Argus system. 


\subsection{Determination of sheet metal properties}

To determine the sheet metal properties the uniaxial tensile test was carried out. The mechanical properties (Table 1) were determined on Zwick ZTS 30 machine, equipped with an automatic multiextensometer to measure the elongation and the second extensometer to measure the width of the specimen during the test.

Table 1 Mechanical properties of AMS 5512 steel sheet with a thickness of $0.8 \mathrm{~mm}$, calculated using averaging formula $\mathrm{x}_{\mathrm{av}}=\left(\mathrm{x}_{0}+2 \mathrm{x}_{45}+\mathrm{x}_{90}\right) / 4$

\begin{tabular}{|lccccc|}
\hline $\begin{array}{c}\text { Specimen } \\
\text { orientation }\end{array}$ & $\begin{array}{c}\text { Yield } \\
\text { stress }\end{array}$ & $\begin{array}{c}\text { Ultimate } \\
\text { strength }\end{array}$ & \multicolumn{2}{c|}{$\begin{array}{c}\text { Strain hardening } \\
\text { parameters }\end{array}$} & $\begin{array}{c}\text { Lankford } \\
\text { coefficient }\end{array}$ \\
& $\begin{array}{c}\boldsymbol{\sigma}_{\mathbf{0 . 2}} \\
\mathbf{M P a}\end{array}$ & $\begin{array}{c}\boldsymbol{\sigma}_{\mathbf{M}} \\
\mathbf{M P a}\end{array}$ & $\begin{array}{c}\mathbf{C} \\
\mathbf{M P a}\end{array}$ & $\mathbf{n}$ & $\mathbf{r}$ \\
\hline $0^{0}$ & 322 & 656 & 1790 & 0.361 & 0.525 \\
$45^{0}$ & 321 & 611 & 1629 & 0.361 & 1.354 \\
$90^{0}$ & 308 & 662 & 1728 & 0.350 & 1.019 \\
Mean values & 318 & 647 & 1694 & 0.358 & 1.063 \\
\hline
\end{tabular}

The method of draw piece strain measuring by using Argus system is shown in Fig. 3. Change of the camera position in two planes take place during measuring geometrically complex draw piece. At each camera position shown in Fig. 3a (the object observation level) the measured draw piece is rotated of 3600 in the plane shown in Fig. 3b.

a)

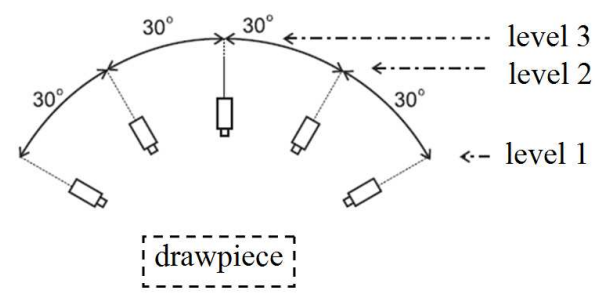

b)

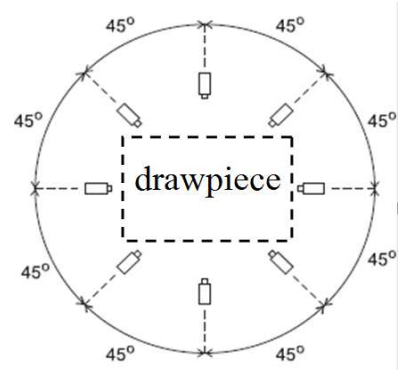

Fig. 3 The method of strain measurement using the Argus system - camera positions during the measurement: side view -(a) and top view -(b)

For draw piece having a simplified geometry less levels of observation are used. To determine the course of FLC the Marciniak-Kuczyński (MK) method was used, involving the draw piece forming using a pipe shape punch [20-22]. Measurement of strain in the plane of draw piece was made after its ductile fracturing using Argus 5M photogrammetric system. Determination of forming limits strain (major and minor) was based on the PN-EN ISO 12004-2 base. The Marciniak test was carried out with the speed of the punch of $1.0 \mathrm{~mm} / \mathrm{s}$, at $23{ }^{\circ} \mathrm{C}$. The test was performed on electrochemically etched specimens with measuring circular dots grid with regular spacing and diameter of $2 \mathrm{~mm}$. In the study three samples at each, characteristic geometry type was used. Strain measurement was performed in the central drawpiece zone, close to the separation of the material (Fig. 4), which should occur in the frictionless zone. The results of strain measurement allowed constructing the FLC directly from Argus program (Fig. 5). 
a)

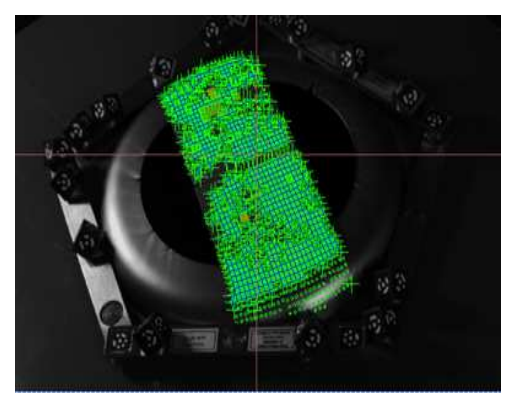

b)

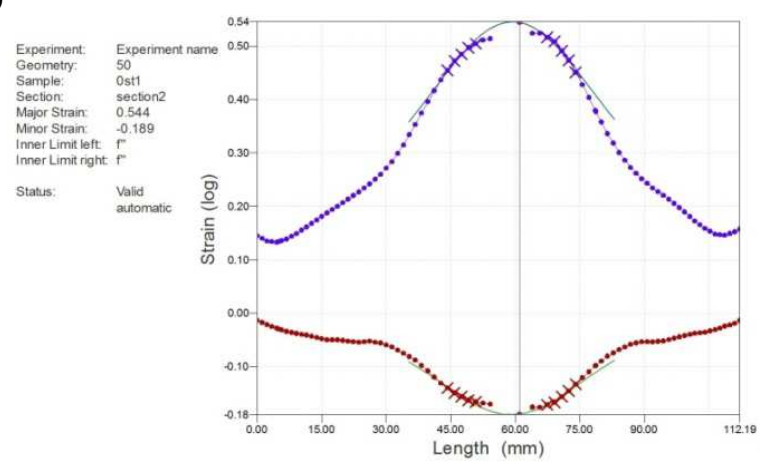

Fig. 4 Strain meshing stage on the measured drawpiece surface for the MK method -(a), example of the forming limit strains determination according to EN ISO 12004 for the chosen specimen geometry -(b)

a)

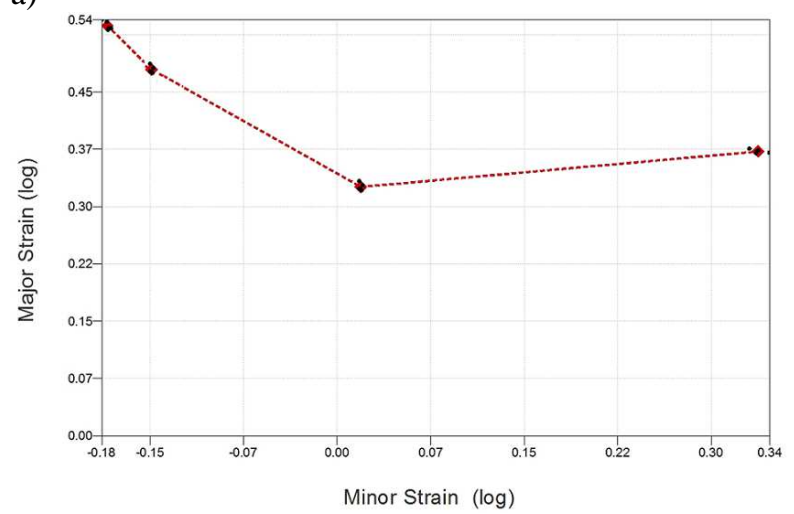

b)

\begin{tabular}{|cc|}
\hline $\begin{array}{c}\text { Minor strain } \\
\varphi_{2}\end{array}$ & $\begin{array}{c}\text { Major strain } \\
\varphi_{1}\end{array}$ \\
\hline \hline$-0,184$ & 0,537 \\
$-0,149$ & 0,479 \\
0 & 0,327 \\
0,338 & 0,372 \\
\hline
\end{tabular}

Fig. 5 The experimental FLC carried out directly using Argus program -(a), together with a table of values for steel AMS 5512 of thickness equals $0.8 \mathrm{~mm}$-(b)

\section{Results and discussion}

To compare the experimental and numerical simulation results the most representative and easily verifiable thickness distributions, along the radius of the draw piece were chosen. The same sheet rolling direction was taken into account, selecting the same orientation of sections. The thickness distributions obtained in simulations (Fig. 6) show mostly sufficient compliance with the results of measurement using of the Argus. However, the main variance in the results takes place around the draw piece perimeter, represented by the A area. Unexpected difference is as follows: the results of the eta/Dynaform indicate a thinning in this area, and the measurements made using photogrammetric systems indicate thickening. Additional measurements using a standard instrument with a dial gauge support thinning in this area. The sheet metal in the analysed area has a radius of about $3.5 \mathrm{~mm}$.

Comparison of thickness changes in the draw piece along its chosen radius, obtained using: simulation, Argus measurements system, and using a classical sensor (for selected points) is given in Fig. 7. The best simulation results were obtained assuming different friction coefficient for contact bodies i.e. for the case of 4 (Table 2). But these are marginal differences - it seems that they are below the steel sheet thickness tolerance. 
a)
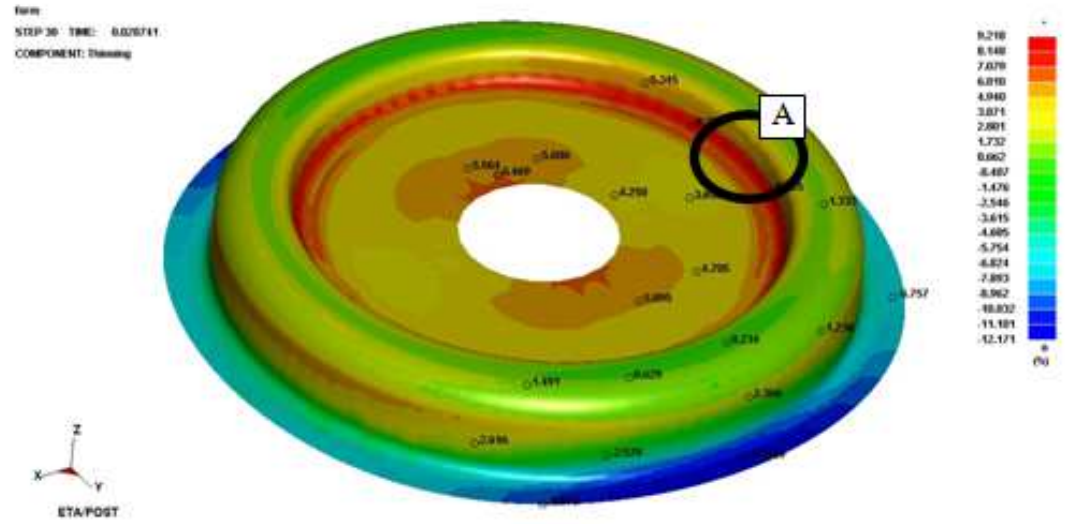

b)

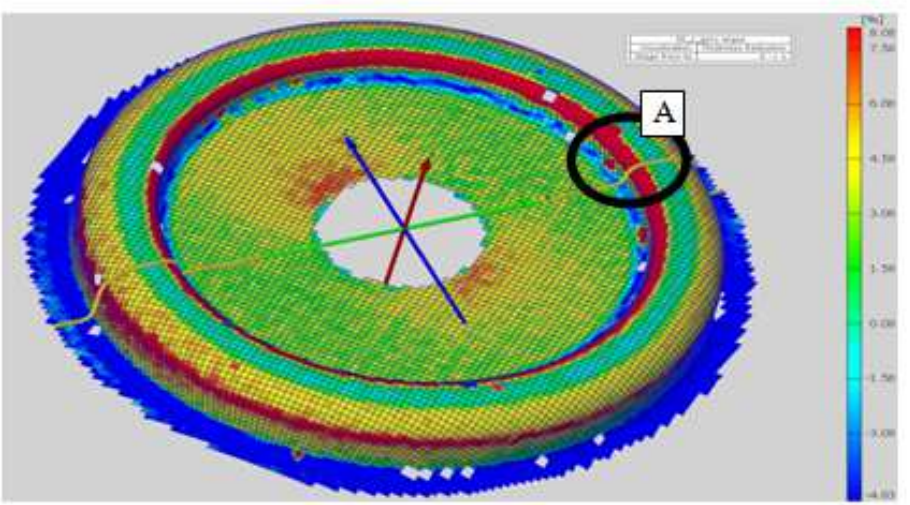

Fig. 6 Drawpiece thickening areas determined by eta/Dynaform - (a) and by Argus measurement - (b)

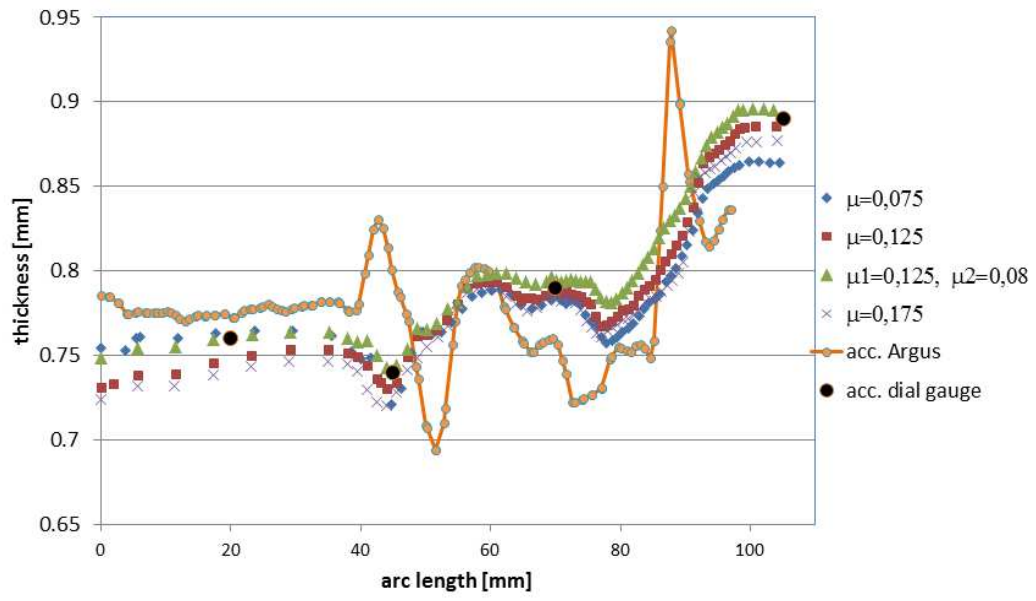

Fig. 7 The comparison of thickness distribution along the radius of the draw piece for the blankholder load of $3 \mathrm{MPa}$, for simulation, Argus system measurement and sensor (dial gauge) measuring 
The use of different blankholder force value changes the distribution of draw piece thickness. Analyzing the thickness distributions obtained by using Argus system, it was found that the assumed range of applied blankholder load has little effect on the distribution of draw piece thickness. These results are shown in Fig. 8.

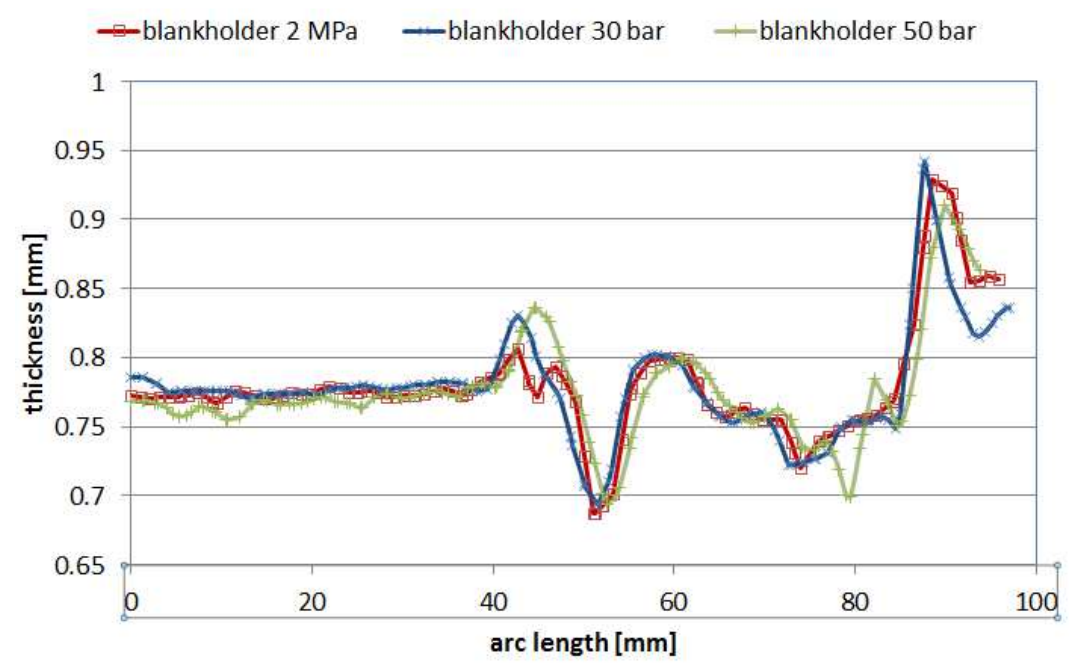

Fig. 8 Comparison of thickness distribution for different blankholder load values

\section{Conclusions}

In the experiments with the Argus photogrammetric system the following applications of this system were found: FLC determination, sheet metal forming process evaluation with respect to the material limits, the determination of real strain to estimate thinning areas in a draw piece, the possibility of direct experimental verification of computer simulation results for the etalDynaform, the use of system as a tool to support the selection of boundary conditions in simulations of the sheet metal forming process. It was also found that this system does not provide acceptable accuracy in the measurement of certain areas of draw piece, especially those that include internal, small radii. There is no assurance that the use of smaller measuring grid can eliminate this problem.

\section{References}

[1] E. Carasusan, F. Canal: An automated procedure for non-contact strain analysis of sheet metal parts, In: ETFA 2003, Lisbon, Vol. 722, p. 724-731

[2] M.P. Sklad: Journal of Materials Processing Technology, Vol. 145, 2004, p. 377-384

[3] S. B. Quan, J. Liang: Optics and Lasers in Engineering, Vol. 50, 2012, p. 1186-1195

[4] J. Vogel, D. Lee: Journal of the Minerals Metals \& Materials Society, Vol. 42, 1990, p. 8-13

[5] J-J. Orteu, V. Garric, M. Devy: Camera calibration for 3D reconstruction: application to the measurement of $3 D$ deformations on sheet metal parts, In: SPIE 1997, Munich, Eds. P. Refregier, R-J. Ahlers, p. 252-263

[6] Z. Hu, H. Xie, J. Lu, H. Wang, J. Zhu: Applied Optics, Vol. 50, 2011, p. 6239-6247

[7] B. Pan, A. Asundi, H. Xie, J. Gao: Optics and Lasers Engineering, Vol. 47, 2009, p. $865-874$ 
[8] J. Vogel, D. Lee: Journal of Material Shaping Technology, Vol. 6, 1988, p. 205-216

[9] A. Andersson, P. Thilderkvist, M. Liljengre: Journal of Materials Processing Technology, Vol. 200, 2008, p. 1-11

[10] Y.Y. Chu, R.S. Lee, V. Psyk, A.E. Tekkaya: Journal of Materials Processing Technology, Vol. 212, 2012, p. 1314-1323

[11] GOM GmbH. Argus optical forming analysis. User's Manual, V4.7.4-2; 2001

[12] Q. Situ, M.K. Jain, D.R. Metzger: International Journal of Mechanical Sciences, Vol. 53, 2011, p. 707-719

[13]A. Meyer, B. Wietbrock, G. Hirt: International Journal of Machine Tools \& Manufacture, Vol. 48, 2008, p. 522-531

[14]M. Schneider, H. Friebe, K. Galanulis: Validation and optimization of numerical simulations by optical measurement of tools and parts, In: IDDRG 2008, Olofström, p. $327-332$

[15] K. Galanulis, A. Hofmann: Determination of Forming Limit Diagrams using an optical Measurement System, In: SheMet'99, Erlangen, p. 245-252

[16] T. Balawender, T. Sadowski, M. Knieć: Archives of Metallurgy and Materials, Vol. 56, 2011, p. 339-446

[17]P. Solfronk, J. Sobotka, P. Doubek, M. Kolnerova: Utilization of forming tool with variable blankholder force for drawing of al alloys, In: Metal 2011, Brno, p. 53-58

[18] H. Hoffman, C. Vogl: CIRP Annals, Vol. 52, 2003, No. 1, p. 217-220

[19] eta/Dynaform - user manual

[20]Z. Marciniak, K. Kuczyński: International Journal of Mechanical Sciences, Vol. 9, 1967, p. $609-620$

[21] Aramis, Argus, Sview - user manual - software - FLC Computation v 6.1.1 by GOM GmbH, Germany

[22]W. Frącz, F. Stachowicz: Metallurgy, Vol. 51, 2012, p. 161-167

\section{Acknowledgement}

Experiments were performed using equipments completed thanks to financial support of UDARPPK.01.03.00-18-003/10 and POPW 01.03.00-18-012/09-00 and co-financed by the European Union from the European Regional Development Fund within Regional Operational Programme for the Podkarpackie Region for the years 2007-2013. 